\title{
Monoclonal antibodies against the human sodium iodide symporter: utility for immunocytochemistry of thyroid cancer
}

\author{
M R Castro, E R Bergert, T G Beito ${ }^{1}$, P C Roche ${ }^{2}$, S C Ziesmer², \\ S M Jhiang ${ }^{3}$, J R Goellner ${ }^{2}$ and J C Morris
} Division of Endocrinology and Metabolism, Mayo Clinic and Mayo Graduate Medical School, Rochester, Minnesota, USA
${ }^{1}$ Division of Immunology, Mayo Clinic and Mayo Graduate Medical School, Rochester, Minnesota, USA
${ }^{2}$ Division of Pathology, Mayo Clinic and Mayo Graduate Medical School, Rochester, Minnesota, USA
${ }^{3}$ Department of Physiology and Internal Medicine, Ohio State University, Columbus, Ohio, USA
(Requests for offprints should be addressed to J C Morris, Division of Endocrinology, Mayo Clinic, 200 First Street SW, Rochester, Minnesota 55905, USA;
Email: Morris.John@Mayo.edu)

\begin{abstract}
The recent cloning of the thyroidal protein that is responsible for iodide transport, the sodium iodide symporter (hNIS), has made possible studies designed to characterize its structure, function and expression in thyroidal tissues. Using a mannose binding protein (MBP)-hNIS fusion protein as antigen, we have developed mouse monoclonal antibodies against hNIS to utilize as tools in such studies. Twenty-four clones were initially recovered which recognized the MBP-hNIS fusion protein, but only two of them were specific for hNIS while the others recognized MBP alone. Both antibodies were found to be immunoglobulin G (IgG) $1 \kappa$ (kappa). The specificity of antibodies was tested by Western blotting using membranes prepared from COS-7 cells transiently transfected with the pcDNA3 plasmid containing the full-length hNIS cDNA, or cells transfected with the pcDNA3 vector. A major band with a molecular weight (MW) of $\sim 97 \mathrm{kDa}$, and several minor bands with MW of
\end{abstract}

$\sim 160 \mathrm{kDa}, \sim 68 \mathrm{kDa}, \sim 30 \mathrm{kDa}$ and $\sim 15 \mathrm{kDa}$, were detected specifically in the hNIS-transfected cells. After enzymatic deglycosylation, the major band was present at $68 \mathrm{kDa}$, as expected based upon the amino acid sequence of hNIS. Immunohistochemistry was performed with several different types of thyroid tissue and non-thyroidal tissues, using the monoclonal antibodies. Strong immunostaining was observed in Graves' tissue, with intermediate staining in papillary and follicular thyroid cancers and an absence of staining in Hürthle cell cancer. The staining was specific for the follicular epithelium and was concentrated in the basolateral portion of the cell membrane. These monoclonal hNIS antibodies should prove useful in the characterization of NIS expression in benign and malignant thyroid tissue and in studies characterizing its structure and function.

Journal of Endocrinology (1999) 163, 495-504

\section{Introduction}

Recently, a new thyroid protein that is important in the physiology of thyroid hormonogenesis has been cloned and characterized, the thyroid iodide transporter (Dai et al. 1996). This glycoprotein, a membrane-bound structure, functions as a sodium iodide symporter (NIS), and is responsible for the thyroid gland's ability to concentrate iodide up to 40-fold with respect to plasma. Prior studies have localized it to the basolateral region of thyroid follicular cells (Carrasco 1993). The original model suggested that NIS was characterized by 12 membrane spanning segments separated by 13 extra-membranous domains (ExMD) with one of these ExMD lying at each end of the molecule. However, more recently, a modification of the original model has been proposed, containing 13 membrane spanning segments and 14 ExMDs, with the amino terminus being extracellular and the carboxy terminus lying in the intracellular space (Levy et al. 1998) (Fig. 1). Through molecular cloning techniques, the amino acid sequence of the human NIS (hNIS) has been delineated (Smanik et al. 1996).

The importance of the characterization and study of NIS is related to its role in thyroid function, the pathogenesis of thyroid disease, and its expression or lack thereof in thyroid malignancies. It is the activity of this molecule that makes possible the most specific form of therapy for differentiated thyroid cancer, radioiodine. Expressed predominantly, although not exclusively, in thyroid tissue, it has also been suggested that NIS may represent an autoantigen in autoimmune disease of the thyroid (Morris et al. 1997).

In order to study the structure, function, and expression of NIS in vitro, antibodies with high affinity and specificity 


\section{Human Sodium/lodide Symporter}

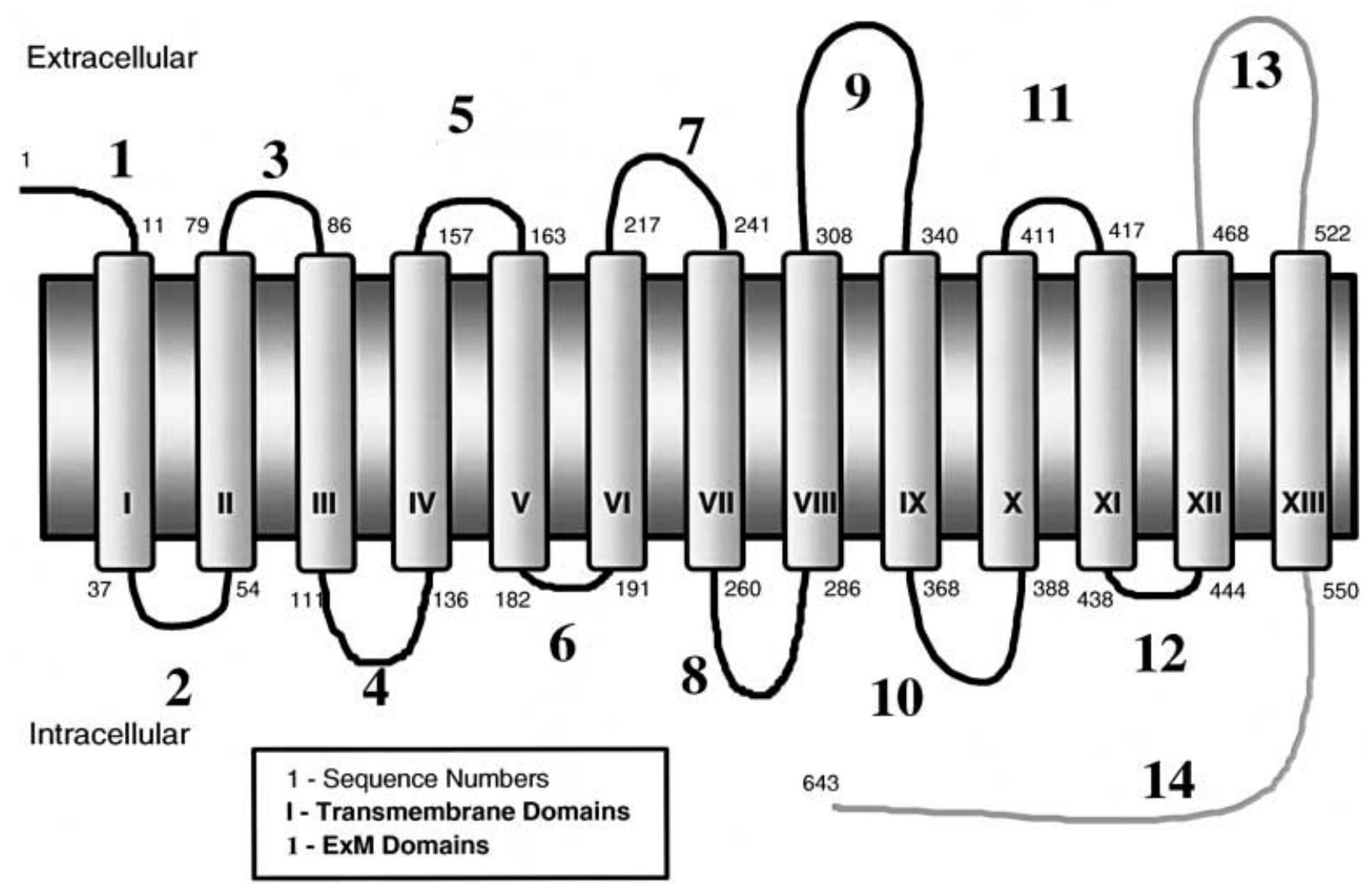

Figure 1 Revised model of the human sodium iodide symporter (adapted from Levy et al. 1998). In lighter gray are the amino acid residues that comprised the hNIS portion of the fusion protein against which monoclonal antibodies were generated.

are needed as reagents. This report describes the development of such reagents and initial studies of the NIS expression in thyroid tissues.

\section{Materials and Methods}

\section{Mannose binding protein (MBP)-hNIS fusion protein}

MBP-hNIS fusion protein was generated as previously described (Jhiang et al. 1998). The final product consisted of the amino acid residues 468-643 of hNIS attached to $\mathrm{MBP}$ and it was purified using amylose resin.

\section{Immunizations}

The fusion protein was emulsified in equal ratios of Freund's complete adjuvant and $0.9 \%$ saline to a final concentration of $100 \mu \mathrm{g} / \mathrm{ml}$. Five mice were immunized subcutaneously with $50 \mu \mathrm{g}$ of the protein and boosted with an equal dose twice at 3-week intervals. Ten days after each boost, the mice were bled and their sera tested by enzyme-linked immunosorbent assay (ELISA) for relevant antibody activity to the MBP-hNIS fusion protein. A final boost was given on week 10 by i.v. injection into a tail vein of the mouse that demonstrated the highest antibody titer of $100 \mu \mathrm{g}$ of the MBP-hNIS fusion protein diluted in $0 \cdot 9 \%$ saline, to a final volume of $1 \mathrm{ml}$.

\section{Monoclonal antibodies (MoAbs) production}

The protocol used for generation of B cell hybridomas has previously been described (De St Groth \& Scheidegger 1980).

The studies and procedures were reviewed and approved by the Mayo Foundation Institutional Animal Care and Use Committee.

\section{Enzyme-linked immunosorbent assay}

Microtiter plates were coated with $10 \mu \mathrm{g} / \mathrm{ml}$ MBP-hNIS fusion protein or MBP only and incubated overnight at $4{ }^{\circ} \mathrm{C}$. Non-specific binding sites were blocked with $1 \%$ 
Table 1 Human NIS peptides

\begin{tabular}{|c|c|c|c|}
\hline \multirow[b]{2}{*}{ ExMD } & Number & Sequence & $\begin{array}{l}\text { Amino } \\
\text { acids }\end{array}$ \\
\hline & & & \\
\hline 10 & $368-388$ & EDLIKPRLRSLAPRKLVIISK & 21 \\
\hline 12 & $437-444$ & LPACNTPG & 8 \\
\hline 13a & $468-487$ & PSEQTMRVLPSSAARCVALS & 20 \\
\hline $13 b$ & $483-502$ & CVALSVNASGLLDPALLLPAN & 20 \\
\hline $13 c$ & $498-522$ & LLPANDSSRAPSSGMDASRPALADS & 25 \\
\hline $14 \mathrm{a}$ & $550-569$ & TGPTKRSTLAPGLLWWDLAR & 20 \\
\hline $14 b$ & $565-584$ & $\underline{\text { WDLARQTASVAPKEEVAILD }}$ & 20 \\
\hline $14 c$ & $580-599$ & VAILDDNLVKGPEELPTGNK & 20 \\
\hline $14 d$ & $595-614$ & PTGNKKPPGFLPTNEDRLFF & 20 \\
\hline $14 \mathrm{e}$ & $610-629$ & $\overline{\text { DRLFFLGQKELEGAGSWTPC }}$ & 20 \\
\hline $14 f$ & $625-643$ & 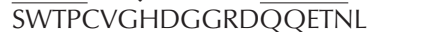 & 19 \\
\hline
\end{tabular}

Underlined residues represent regions of overlap with neighboring peptides.

BSA in PBS containing 0.05\%-Tween-20 (PBS-T) and incubated at $37^{\circ} \mathrm{C}$ for $1 \mathrm{~h}$. Mouse sera diluted in PBS-T, or hybridoma supernatant media when screening clones, were added to each well. Alkaline phosphatase goat anti-mouse (GAM; Sigma, St Louis, MO, USA) at 1:5000 dilution was used as the second stage antibody and nitrophenyl phosphate substrate in $1 \mathrm{mM} \mathrm{MgCl}, 0.5 \mathrm{mM}$ $\mathrm{ZnCl}_{2}, \mathrm{pH} 9 \cdot 8$ was used for detection. Optical density (O.D.) was read at $405 \mathrm{~nm}$. Appropriate negative controls with irrelevant mouse immunoglobulin $G(\operatorname{IgG})$ at identical dilutions, and positive controls were performed with each assay.

Hybridomas producing antibodies specific for hNIS rather than the MBP portion of the fusion protein were selected by differential screening. This was performed by initially selecting all positive clones obtained after the second round of subcloning and rescreening them simultaneously against both MBP-hNIS fusion protein and MBP. Only those hybridomas that tested positive against the former but negative against the latter were further subcloned.

The immunoglobulin class, subclass and light chain type of the monoclonal antibodies were determined by using a mouse hybridoma subtyping kit (Boehringer $\mathrm{GmbH}$, Mannheim, Germany), according to instructions from the manufacturer.

\section{Peptide production and epitope mapping}

Peptides encompassing the amino acid sequences of the 10th, 12th, 13th and 14th ExMDs of hNIS were synthesized by solid phase synthesis and subsequently purified by HPLC on a C-18 column (Morris et al. 1990). The sequences were taken from Smanik et al. (1996). The amino acid sequences of the peptides synthesized are shown in Table 1. The purity and accuracy of the peptides was assessed by amino acid analysis and mass spectrometry. Plates coated in triplicate with $10 \mu \mathrm{g} / \mathrm{ml}$ of each of the peptides described were subsequently incubated with antibody-rich ascites fluid (FP-5A and FP-13) diluted 1:5000 in $0 \cdot 1 \%$ BSA-PBS-T, and ELISA was performed as described. Appropriate negative and positive controls were performed in each case.

\section{Functional expression of hNIS in COS-7 cells}

COS-7 cells were grown in Dulbecco's modified Eagle's medium (Gibco-BRL, Gaithersburg, MD, USA) supplemented with $10 \%$ fetal bovine serum, 1\% glutamine and $1 \%$ penicillin/streptomycin. Fresh media were replaced every other day until the cells reached approximately $75 \%$ confluency, at which time they were subcultured into 12 -well plates at a density of $\sim 100000$ cells/well. These cells were transfected by the lipofectamine technique (Gibco-BRL) with a pcDNA3 plasmid containing the gene for the full-length hNIS (amino acids 1-643) or the pcDNA3 vector only. Forty-eight hours after transfection, iodide uptake was assessed as previously described (Weiss et al. 1984). hNIS-transfected cells were incubated with various dilutions $(1: 10-1: 1000)$ of the monoclonal antibodies for $1 \mathrm{~h}$ at $37^{\circ} \mathrm{C}$, in order to assess their effect on NIS activity.

\section{Preparation of membranes}

Membranes from COS-7 cells were prepared by a modification of a previously described procedure (Kaminsky et al. 1994). In brief, the transfected cells were washed with PBS, harvested and resuspended in ice-cold $250 \mathrm{mM}$ sucrose, $10 \mathrm{mM}$ Hepes pH 7·5, 1 mM EDTA, containing aprotinin $(10 \mu \mathrm{g} / \mathrm{ml})$, leupeptin $(10 \mu \mathrm{g} / \mathrm{ml})$ and $1 \mathrm{mM}$ phenylmethylsulfonyl fluoride. The samples were centrifuged twice at $500 \times \mathrm{g}$ for $15 \mathrm{~min}$ at $4{ }^{\circ} \mathrm{C} . \mathrm{Na}_{2} \mathrm{CO}_{3}$ $(100 \mathrm{mM})$ was added to the resulting supernatant and shaken for $45 \mathrm{~min}$ at $4{ }^{\circ} \mathrm{C}$, and then centrifuged at $100000 \times \boldsymbol{g}$ for $15 \mathrm{~min}$. The pellet obtained was resuspended in $500 \mu \mathrm{l}$ of a buffer containing $250 \mathrm{mM}$ sucrose, $10 \mathrm{mM}$ Hepes $\mathrm{pH} 7 \cdot 5,1 \mathrm{mM} \mathrm{MgCl}_{2}$ and aliquoted for future use. Protein content was quantitated using the Bio-Rad DC protein assay (BioRad, Hercules, CA, USA).

\section{Western blot analyses}

Membrane samples were prepared for electrophoresis by addition of NuPAGE SDS sample buffer with or without reducing agent, (NuPAGE; Novex, San Diego, CA, USA). The samples were then incubated at $70^{\circ} \mathrm{C}$ in a water bath for $10 \mathrm{~min}$ and $2 \mu \mathrm{g}$ membrane protein from cells transfected with FL-hNIS or control vector were loaded onto a $4-12 \%$ acrylamide gradient gel. After electrophoresis, the proteins were transferred to nitrocellulose membranes by electroblotting at $25 \mathrm{mV}$ for $1 \mathrm{~h}$. 
Nonspecific binding sites were blocked with $5 \%$ milk in

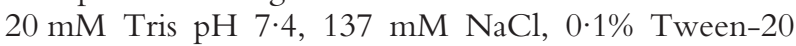
(TBST) for $1 \mathrm{~h}$. The membranes were then incubated for $2 \mathrm{~h}$ at room temperature with the antibody preparations diluted 1:5000 with TBST. After this, they were washed 3 times with TBST and incubated for $1 \mathrm{~h}$ with peroxidase-conjugated goat anti-mouse IgG (Jackson ImmunoResearch Laboratory, West Grove, PA, USA) at a 1:5000 dilution. After washing with the same buffer 4 times, the proteins were visualized with chemiluminescent detection reagents (ECL; Amersham, Arlington Heights, IL, USA).

Deglycosylation of membrane proteins was carried out with N-glycosidase F (New England Biolabs, Beverly, MA, USA) according to the manufacturer's protocol, as previoulsy described (Jhiang et al. 1998).

\section{Immunostaining}

Paraffin-embedded sections of normal thyroid gland, Graves' disease thyroid gland, papillary, follicular and Hürthle cell thyroid cancers, as well as some non-thyroidal tissues (skin, adipose tissue) were stained by the immunoperoxidase method. The tissue sections were obtained from the archives of our Pathology department and deparaffinized by serial passages in xylene and graded alcohol, and endogenous peroxidase activity was blocked by incubation of slides in a $50 \%$ by volume solution of $3 \% \mathrm{H}_{2} \mathrm{O}_{2} /$ methanol for $10 \mathrm{~min}$. Subsequently, the slides were subjected to antigen retrieval with $10 \mathrm{mM}$ citrate buffer steam for $30 \mathrm{~min}$ and then rinsed for $2 \mathrm{~min}$ in tap water. Non-specific binding sites were blocked by applying $5 \%$ normal goat serum (NGS) diluted in PBS-T and incubated at room temperature for $30 \mathrm{~min}$. Primary antibody (FP-13) diluted 1:1500 in 1\% NGS-PBS-T was added and slides incubated for $1 \mathrm{~h}$ at room temperature. After this, they were rinsed in tap water for $2 \mathrm{~min}$ and PBS-T for another $2 \mathrm{~min}$ and subsequently incubated for 20 min with biotin-SP-conjugated goat-anti-mouse IgG at a 1:200 dilution in 1\% NGS-PBS-T. After rinsing again as described above, the slides were incubated for $20 \mathrm{~min}$ in peroxidase-conjugated streptavidin (DAKO, Copenhagen, Denmark) at a 1:300 dilution in the same buffer, rinsed and then incubated for $2 \mathrm{~min}$ in sodium acetate solution ( $\mathrm{pH} \mathrm{5.2)} \mathrm{followed} \mathrm{by} 15 \mathrm{~min}$ in 3-amino9-ethyl-carbazole (AEC) substrate solution (Sigma). This solution was prepared by dissolving one $20 \mathrm{mg}$ AEC substrate tablet in $5 \mathrm{ml}$ dimethyl formamide, adding $95 \mathrm{ml}$ of a sodium acetate solution, $\mathrm{pH} 5.2$ and $1 \mathrm{ml} 3 \%$ hydrogen peroxide. The solution was filtered prior to use. Finally, the slides were rinsed with tap water for $1 \mathrm{~min}$, counterstained with hematoxylin and then rinsed under running tap water for $5 \mathrm{~min}$. They were mounted using a glycerol gelatine previously warmed in a water bath.

Review of the charts of the patients whose slides are shown revealed that none of the patients with thyroid

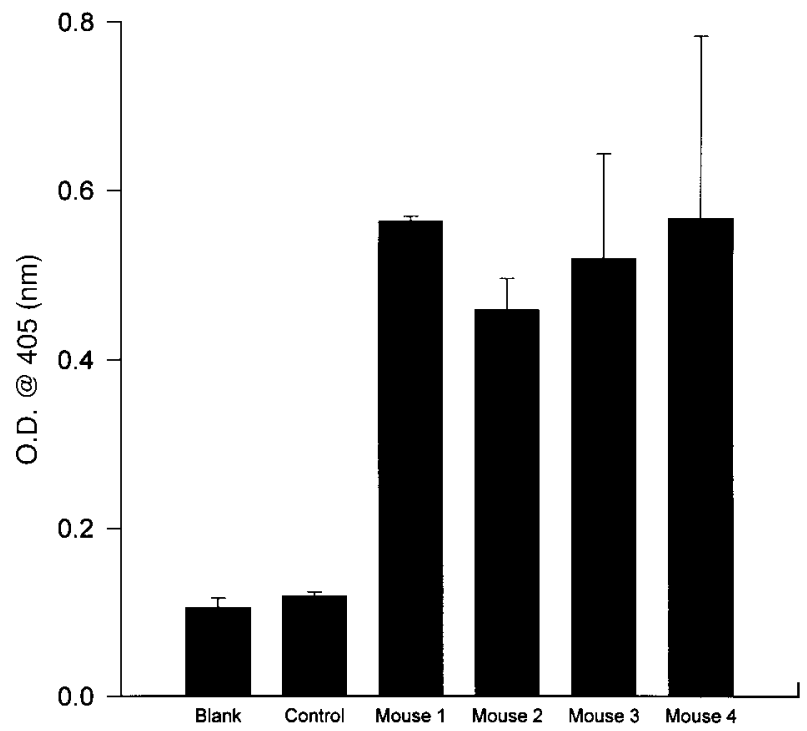

Figure 2 Mouse antibody activity against MBP-hNIS fusion protein measured as optical density (O.D.) at $405 \mathrm{~nm}$ of mouse antibody titers after the second bleed, at 1:5000 dilution in ELISA. Means \pm S.E. are shown.

cancer had received treatment with either thyroid hormone or radioiodine prior to the surgery. The patient with Graves' disease had received treatment with methimazole $(15 \mathrm{mg} /$ day) and Lugol solution for 2 weeks prior to the surgery.

\section{Results}

\section{Mouse antibody titers}

Ten days after the first boost, all mice had developed antibody titers, detectable at 1:10 000 dilution of the serum. After the second bleeding, antibody titers had increased even further. The mouse with the highest titers against MBP-hNIS fusion protein had detectable antibody at 1:50 000 dilution which was 3.6 times the O.D. of the negative control at the same dilution (Fig. 2).

\section{Production of monoclonal antibodies and isotyping}

After fusion and subcloning, twenty-four hybridoma clones were initially identified which recognized the MBP-hNIS fusion protein by ELISA. After differential screening, 2 clones were recovered which recognized MBP-hNIS fusion protein but not MBP (MoAbs FP-5A and FP-13). These clones were specific for hNIS and, on isotyping, were found to be $\operatorname{IgG} 1 \kappa$ (kappa).

\section{Epitope mapping}

The two antibodies obtained, when tested by ELISA against each of the peptides initially described, were found 


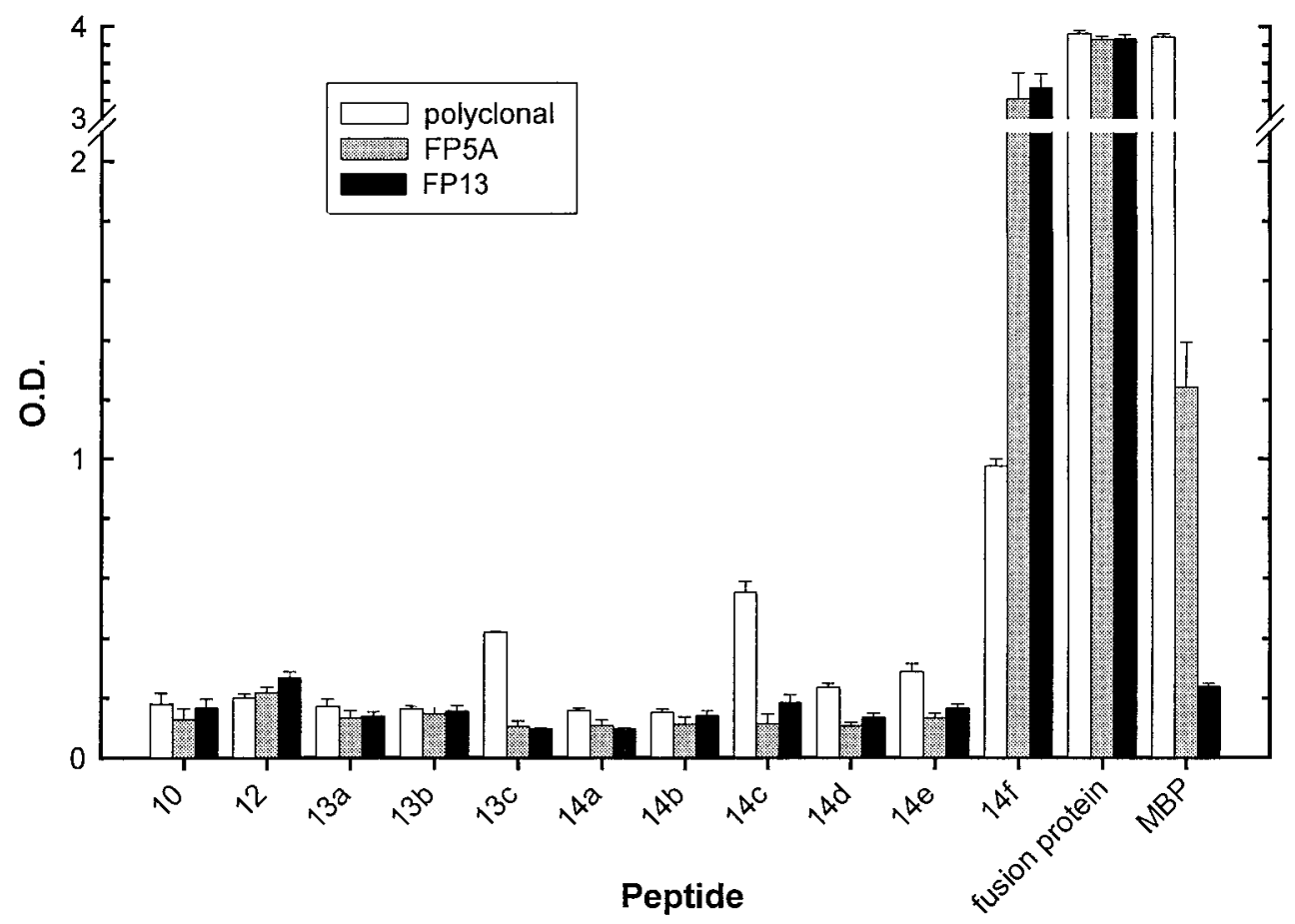

Figure 3 Epitope mapping of antibodies against hNIS: ELISA assay activity of monoclonal and polyclonal anti-MBP-hNIS fusion protein antibodies against hNIS peptides 10 through 14, MBP and MBP-hNIS fusion protein. Both monoclonal antibodies (FP-5A and FP-13) recognized the carboxy-terminus sequence of hNIS (peptide 14f), and the fusion protein, although FP-5A also showed low-level activity against MBP. Polyclonal antibodies showed low-level activity against peptides $13 \mathrm{c}, 14 \mathrm{c}$ and $14 \mathrm{f}$ and strong activity against the fusion protein and MBP. Means \pm S.E. are shown.

to recognize only the peptide containing the amino acid sequence 625-643 (14f) in the carboxy terminus of hNIS (Fig. 3). Antibody FP-5A also showed some level of activity against MBP, although this activity was much lower than that against the MBP-hNIS fusion protein (Fig. 3).

\section{Iodide uptake}

COS-7 cells transiently transfected with the FL-hNIS cDNA clone in the pcDNA3 vector accumulated 23.45fold more $\mathrm{Na}^{125}$ I than cells transfected with the pcDNA3 vector only (Fig. 4) and this uptake was inhibited in the presence of $10 \mu \mathrm{M}$ perchlorate, a known competitive inhibitor of thyroid iodine uptake (Taurog 1996).

\section{Western blotting analysis}

Western blotting was performed to assess recognition of the recombinant hNIS protein, in COS-7 membrane preparations, by the monoclonal antibodies. The hNIS proteins were detected by monoclonal antibodies against the MBP-hNIS fusion protein as a major band with a

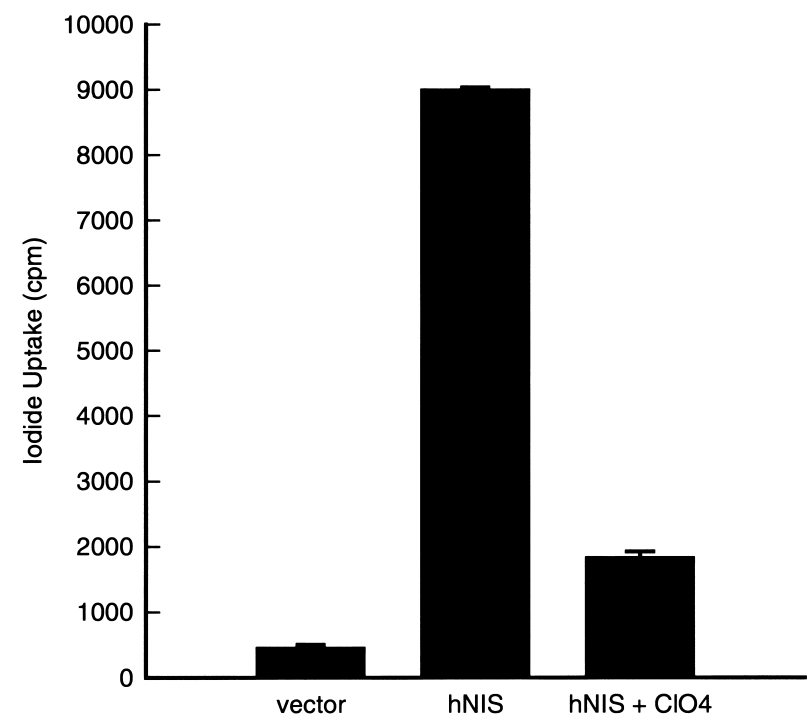

Figure 4 Functional expression of hNIS in COS-7 cells. hNIS-transfected COS-7 cells showed a 23 -fold increase in iodide uptake compared with COS-7 cells transfected with control vector. This uptake was inhibited in the presence of perchlorate (ClO4), a known competitive inhibitor of iodide uptake. 


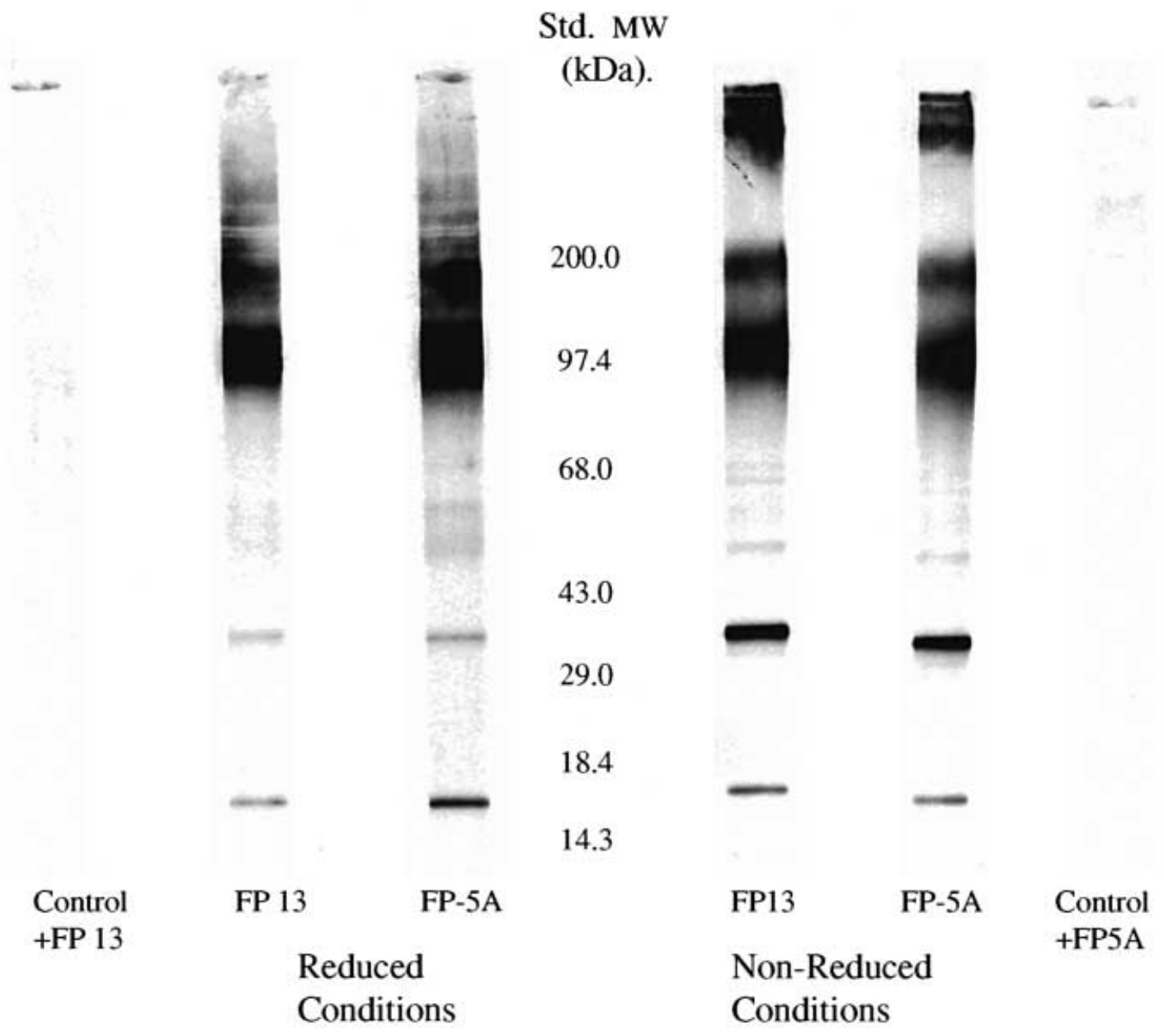

Figure 5 Western blot of hNIS using transfected COS-7 cell membranes. SDS-PAGE was performed under reduced (left) and non-reduced (right) conditions. Note absence of band in cells transfected with control vector incubated with antibody (FP 13 or FP-5A). Also note similar migration of the $97 \mathrm{kDa}$ band and differences between the $30 \mathrm{kDa}$ and $15 \mathrm{kDa}$ bands under both conditions.

molecular weight $(\mathrm{MW})$ of $\sim 97 \mathrm{kDa}$, and several minor bands with MW of $\sim 160 \mathrm{kDa}, \sim 68 \mathrm{kDa}, \sim 30 \mathrm{kDa}$ and $\sim 15 \mathrm{kDa}$, all of them specific for the hNIS-transfected cells as compared with cells transfected with control vector (Fig. 5). The MW of hNIS in membrane fractions subjected to enzymatic deglycosylation was $\sim 68 \mathrm{kDa}$, which was as expected based upon the amino acid sequence of hNIS (Fig. 6, left). After preincubation of the antibody with peptide $14 \mathrm{f}$, the $97 \mathrm{kDa}$ and $68 \mathrm{kDa}$ bands disappeared (Fig. 6, right).

\section{Immunostaining of thyroid and non-thyroidal tissues}

Thyroid tissue from patients with Graves' disease incubated with monoclonal antibody against hNIS showed the most intense immunostaining, which was fairly homogeneous, present in almost all follicles and well localized to the basolateral portion of the follicular cell membrane (Fig. 7A-B). No staining was observed in Graves' tissue incubated with irrelevant antibody (Fig. 7C). Hürthle cell cancers, which are recognized for their common lack of ability to concentrate iodine (Carcangiu et al. 1991, Caplan et al. 1994), did not show staining (Fig. 7D). Intermediate staining was observed in papillary and follicular thyroid cancers and, in these, the staining pattern was distinct from that observed in Graves' tissue, being more diffuse, patchy, and less well localized to the basolateral region (Fig. 7E-G). Immunocytochemistry of normal thyroid tissue showed patchy areas of intense staining, mostly in a follicular pattern alternating with other follicles with minimal or no staining (Fig. 7H). The staining was, in all cases, specific for the follicular epithelium (Fig. 7A-J). After preabsorption of the antibody with the peptide 14f, no immunostaining was 


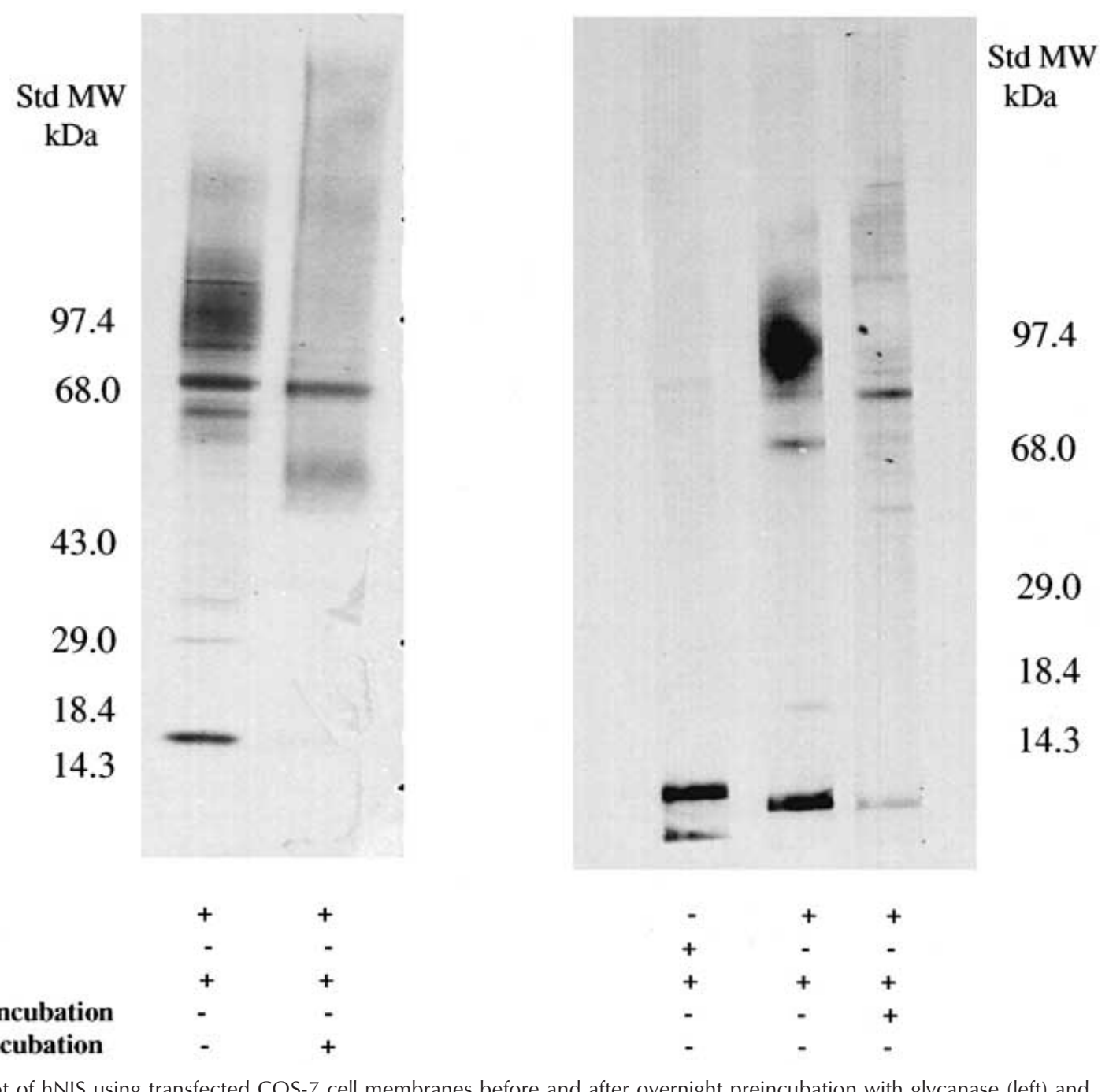

hNIS-COS7 Control-COS7

\section{FP-13}

\section{peptide $14 \mathrm{f}$ preincubation} glycanase preincubation

before and after preincubation with free peptide (14f) (right). Note the disappearance of the $97 \mathrm{kDa}$ band and persistence of the $68 \mathrm{kDa}$ band in the presence of glycanase (left); also note the disappearance of the $97 \mathrm{kDa}$ and $68 \mathrm{kDa}$ bands after preincubation with free peptide.

observed (Fig. 7I-J). Non-thyroidal tissues (skin, adipose tissue) incubated with these antibodies did not show immunostaining (Fig. 7K-L).

\section{Discussion}

We have generated monoclonal antibodies against the human sodium iodide symporter that are capable of recognizing this protein by ELISA, Western blotting and immunohistochemistry with a high degree of specificity.

Western blotting of COS-7 membranes transfected with hNIS showed a major band with a MW $\sim 97 \mathrm{kDa}$ and several other minor bands with MW of $\sim 160 \mathrm{kDa}$, $\sim 68 \mathrm{kDa}, \sim 30 \mathrm{kDa}$ and $\sim 15 \mathrm{kDa}$. These minor bands most likely represent degradation fragments of the protein although further study is required to assess this fully. However, it is also possible that the $\sim 68 \mathrm{kDa}$ band seen in the hNIS-transfected cells represents non-glycosylated hNIS. The MW of the major band of hNIS observed under reduced and non-reduced conditions did not differ (Fig. 5). These results are in agreement with those of Jhiang et al. (1998) using polyclonal antibodies against hNIS. However, significant differences were observed in the intensity of the $30 \mathrm{kDa}$ and the $15 \mathrm{kDa}$ bands when SDS-PAGE was performed under reduced vs nonreduced conditions. Under non-reduced conditions the $30 \mathrm{kDa}$ band was more intense than the $15 \mathrm{kDa}$ band, while the opposite was true when SDS-PAGE was 

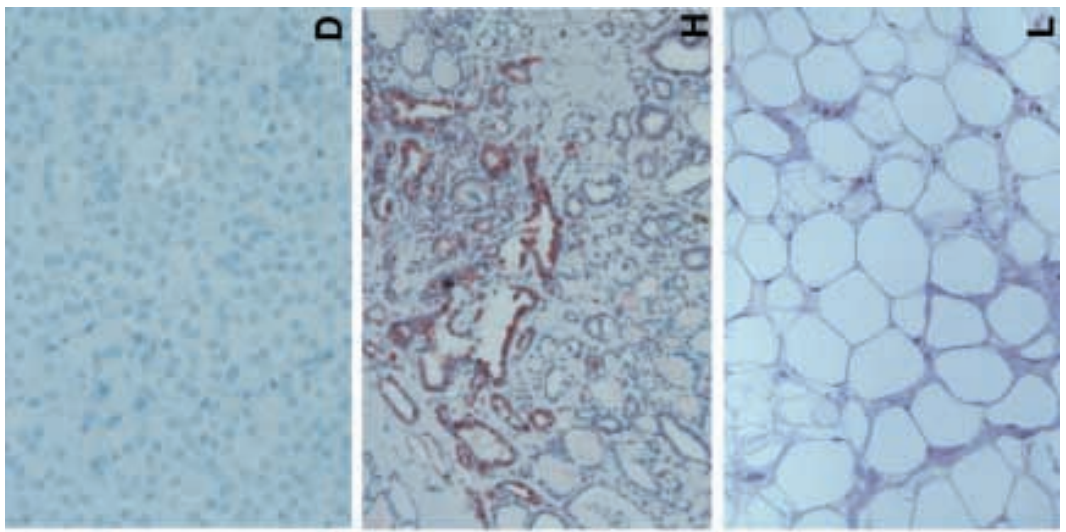

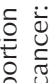
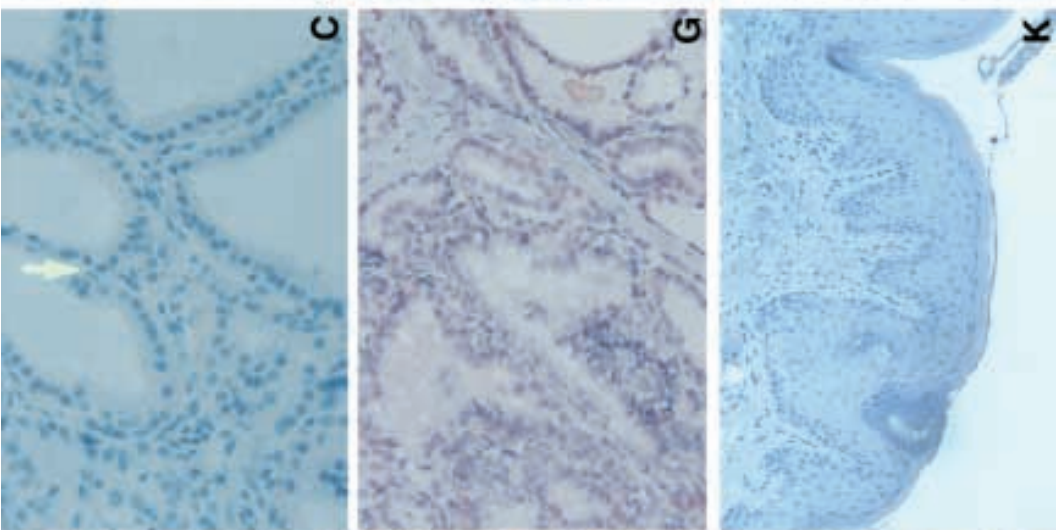

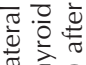

항 $\overrightarrow{=}$

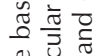

$\stackrel{Ð}{=} \stackrel{\underline{\underline{*}}}{\underline{0}}$

$\cong$ 닌

号岀

的 oi

oo. is

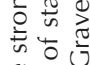

뿬

ब्र纪

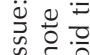

$=$

is 这

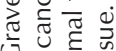

$\overline{0}$

10

政

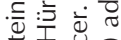

응

웅
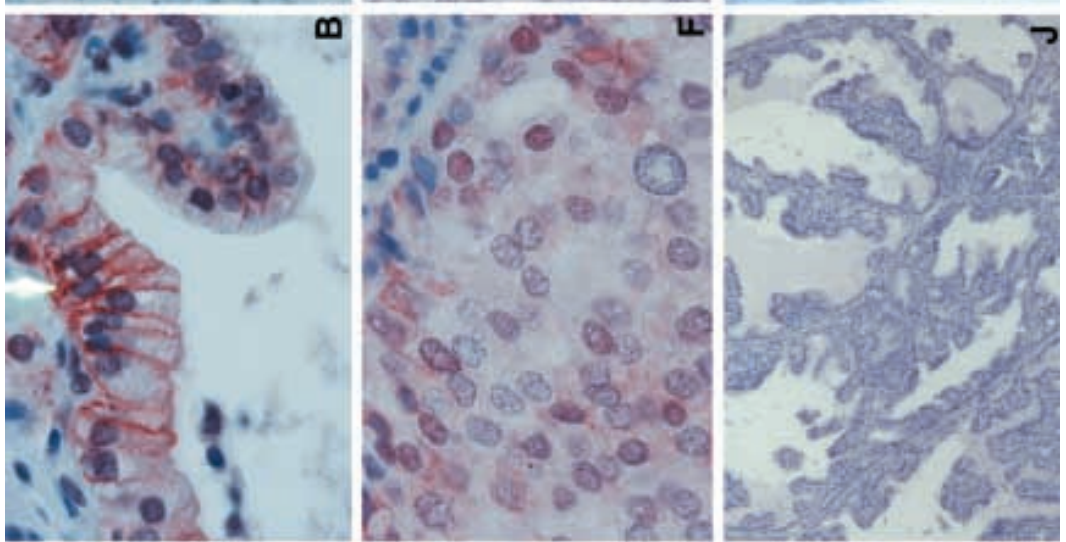

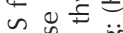

Z施

定

$\sum^{\infty} \frac{1}{0} \alpha^{\circ}$ के

फั

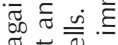

完过

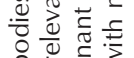

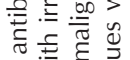

$\frac{\pi}{3}=$

은 월 중

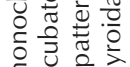

$\varepsilon . \subseteq$ o.
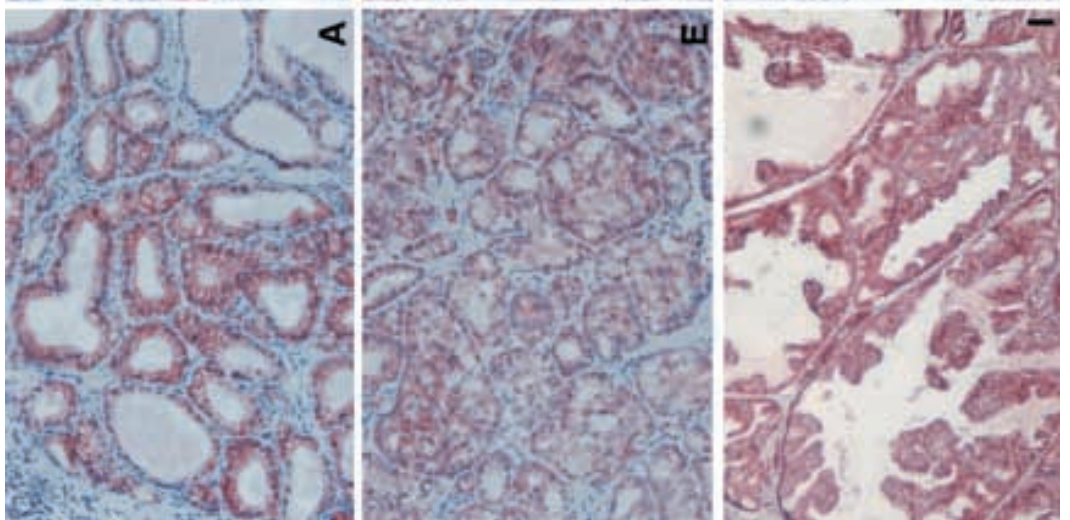

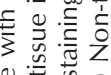

至:

的定立

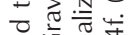

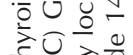

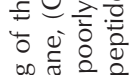

.

है है व

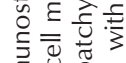

है

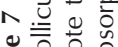

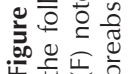


performed after incubating the membranes with the reducing agent. This difference suggests the presence of disulfide bonds in the $30 \mathrm{kDa}$ fragment which are at least partially eliminated in the reduction process, although reduction was probably incomplete since the $30 \mathrm{kDa}$ band faded but did not completely disappear. It has previously been demonstrated that hNIS is a glycoprotein. Its expected $\mathrm{MW}$ in the non-glycosylated form is $\sim 68 \mathrm{kDa}$, similar to that found in non-glycosylated COS-7 cells transfected with hNIS. We found the MW of glycosylated hNIS in our transfected COS-7 cells to be $\sim 97 \mathrm{kDa}$, slightly higher than that previously reported (Jhiang et al. 1998). This difference is most likely due to different conditions of gel electrophoresis or minor differences in the quality or quantity of glycosylation achieved in our system. Our results with the deglycosylated membranes of transfected COS-7 cells are consistent with the expected MW of hNIS.

Neither of the antibodies inhibited iodide uptake in transfected COS-7 cells. This is probably due to the fact that they recognize an epitope which is localized in the intracellular side of the membrane. Antibodies raised against extracellular domains would be helpful in clarifying this question.

The results of the analysis of the activity of our monoclonal antibodies against the different peptides, MBP and the fusion protein, demonstrate the specificity of our antibodies against hNIS. The polyclonal antibodies previously raised against the same MBP-hNIS fusion protein (Jhiang et al. 1998) were analyzed simultaneously with our monoclonal antibodies and found to have a lower level of activity against three different peptides (13c, 14c and 14f) of hNIS, although they also recognized MBP to a much higher degree (Fig. 3). However, the MoAbs were more specific against the $14 \mathrm{f}$ peptide of hNIS, although FP-5A displayed low level activity against MBP as well, albeit to a much lesser degree than either the polyclonal antibodies or its activity against the fusion protein. FP-13 had no activity against MBP. Mammalian cells, on the other hand, do not express bacterial MBP and therefore the activity of the MoAb FP-5A or the polyclonal antibodies against this molecule did not interfere with their ability to recognize hNIS or its peptides by either ELISA or Western blotting analysis.

The results of immunohistochemistry also show that our antibodies are capable of recognizing hNIS with high specificity. The ability of these antibodies to stain different types of thyroid tissue with varying intensity is probably related to the degree of expression of this protein in the different tissues. This is supported by the demonstration of very strong staining in several Graves' disease tissues, the variable although often lower and more patchy staining in certain thyroid cancers, and the lack of significant staining in Hürthle cell cancer tissues, which are notorious for their frequent lack of ability to concentrate radioactive iodine (Carcangiu et al. 1991, Caplan et al. 1994). The specificity of our antibodies for NIS is demonstrated by their ability to recognize only follicular rather than stromal cells, and by the finding that the strongest immunostaining is observed in the basolateral aspect of the follicular cell membrane (Fig. 7A-B), where the iodide symporter has been localized (Carrasco 1993). The lack of immunostaining of non-thyroidal tissues (such as skin and adipose tissue) when incubated with these antibodies also supports their specificity for hNIS.

In summary, we have generated monoclonal antibodies against a fusion protein containing the last extracellular loop and the carboxy terminus of hNIS, which are capable of recognizing this protein with high affinity and specificity and are useful for immunostaining of thyroid tissue. Because the degree of immunostaining probably correlates with the expression of this protein in different thyroid tissues, these antibodies may be useful in predicting the ability of thyroid cancers to concentrate iodine. They may thus prove to be important tools in evaluating the role of NIS expression in the biological behavior of thyroid malignancies.

\section{Acknowledgements}

This project was supported in part by a research grant from the Endocrine Fellows Foundation, and by the Mayo Foundation. The authors wish to thank Charyl Dutton-Gibbs for technical support with several aspects of this project.

\section{References}

Caplan RH, Abellera RM \& Kisken WA 1994 Hürthle cell neoplasms of the thyroid gland: reassessment of functional capacity. Thyroid 4 243-248.

Carcangiu ML, Bianchi S, Savino D, Voynick IM \& Rosai J 1991 Follicular Hürthle cell tumors of the thyroid gland. Cancer 68 1944-1953.

Carrasco N 1993 Iodide transport in the thyroid gland. Biochimica et Biophysica Acta 1154 65-82.

Dai G, Levy O \& Carrasco N 1996 Cloning and characterization of the thyroid iodide transporter. Nature 379 458-460.

De St Groth SF \& Scheidegger D 1980 Production of monoclonal antibodies: strategy and tactics. Journal of Immunological Methods $\mathbf{3 5}$ $1-21$.

Jhiang SM, Cho J-Y, Ryu K-Y, De Young BR, Smanik PA, McGaughi VR, Fischer AH \& Mazaferri EL 1998 An immunohistochemical study of $\mathrm{Na}+/ \mathrm{I}-$ symporter in human thyroid tissues and salivary gland tissues. Endocrinology $1394416-4419$.

Kaminsky SM, Levy O, Salvador C, Dai G \& Carrasco N 1994 $\mathrm{Na}^{+}-\mathrm{I}^{-}$symport activity is present in membrane vesicles from thyrotropin-deprived non- $\mathrm{I}^{-}$-transporting cultured thyroid cells. Proceedings of the National Academy of Sciences of the USA 91 3789-3793.

Levy O, De La Vieja A, Ginter CS, Riedel C, Dai G \& Carrasco N 1998 N-linked glycosylation of the thyroid Na+/I- symporter (NIS). Implications for its secondary structure model. Journal of Biological Chemistry 273 22657-22663. 
Morris JC, McCormick DJ \& Ryan RJ 1990 Inhibition of thyrotropin binding to receptor by synthetic human thyrotropin $\beta$-peptides. Journal of Biological Chemistry 256 1881-1884.

Morris JC, Bergert ER \& Bryant WP 1997 Binding of $\operatorname{IgG}$ from patients with autoimmune thyroid disease to rat sodium iodide symporter peptides: evidence for the iodide transporter as an autoantigen. Thyroid 7 527-534.

Smanik PA, Liu Q, Furminger TL, Ryu K, Xing S, Mazaferri EL \& Jhiang SM 1996 Cloning of the human sodium iodide symporter. Biochemical and Biophysical Research Communications 226 339-345.
Taurog A 1996 Hormone synthesis: thyroid iodine metabolism. In The Thyroid, pp 51-97. Eds LE Braverman \& RD Utiger. Philadelphia: JB Lippincott Company.

Weiss SJ, Philp NJ, Ambesi-Impiombato FS \& Grollman EF 1984 Iodide transport in a continuous line of cultured cells from rat thyroid. Endocrinology 114 1090-1097.

Received 16 November 1998

Revised manuscript received 24 March 1999 Accepted 13 July 1999 